\title{
The ghosts of past and future
}

\section{A memory that works by piecing together bits of the past may be better suited to simulating future events than one that is a store of perfect records.}

\section{Daniel L. Schacter and \\ Donna Rose Addis}

In the days after the 1995 Oklahoma City bombing, the authorities began hunting for a suspect they named John Doe 2. A mechanic had vividly recalled seeing this man with the bomber, Timothy McVeigh, at a body shop where they rented the van used to carry out the crime. But John Doe 2 was never found. Further investigations revealed that the mechanic had mistakenly recalled that an innocent man he saw the next day at the body shop - with someone who looked like McVeigh — had accompanied McVeigh the day before. The mechanic had combined accurate bits of memory from two separate episodes into a single, inaccurate recollection.

As this examplehighlights, memory errors can create confusion in everyday life. But for scientists studying memory, such mistakes are important because they provide critical evidence for the idea that episodic memory - the kind of memory that allows us to remember our personal experiences - is not a literal reproduction of the past, but is instead constructed by pulling together pieces of information from different sources.

Such a characterization of memory is hardly new: the psychologist Frederic Bartlett argued for it in his famous 1932 book Remembering. But we still understand little about how constructive remembering is achieved by the brain, and even less about the function served by such a system. Why are episodic memories created by piecing together bits of information, and not by simply reproducing the past as a video-recorder does? Recent research provides clues to the puzzle, and suggests a novel perspective.

One clue comes from studies indicating that memory errors can reveal the operation of adaptive rather than defective processes. For example, consider the following words: tired, bed, awake, rest, dream, night, blanket, doze, slumber, snore, pillow, peace, yawn and drowsy. When asked whether 'blanket' was on the list (a few minutes after seeing the words), most people correctly recognize that it was; when asked about 'point', they correctly remember that it was not. When asked about 'sleep', most people confidently remember having seen it — but they are wrong. They falsely recognize 'sleep' because they remember that many associated words were present, and mistakenly rely on their accurate memory for the general theme of the list.

Amnesic patients with damage to brain structures, such as the hippocampus, that are required for accurate episodic memory make fewer false-recognition errors than do control subjects, reflecting their poor memory for the theme or gist of the list. Neuroimaging studies using this wordrecall procedure with normal adults have found that both true and false recognition show similar levels of brain activity in the hippocampus and other regions in the parietal and frontal lobes that are usually associated with accurate remembering.

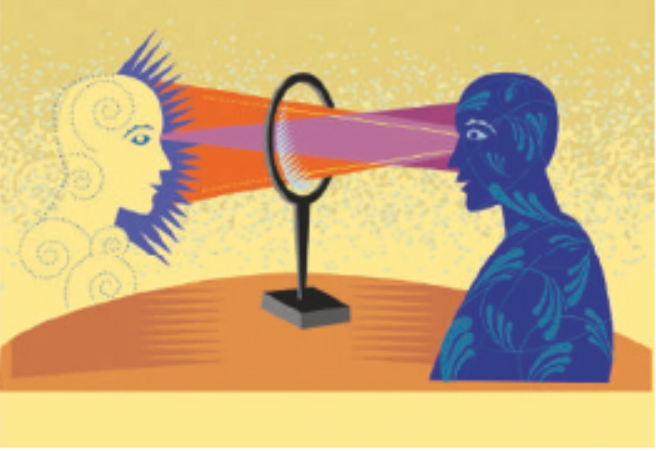

Taken together, neurological and neuroimaging studies suggest that false-recognition errors reflect the healthy operation of adaptive, constructive processes supporting the ability to remember what actually happened in the past. Many researchers believe that remembering the gist of what happened is an economical way of storing the most important aspects of our experiences without cluttering memory with trivial details. We agree. But we also see another important function for constructive memory, one that emerges from an idea that a growing number of researchers are embracing - that memory is important for the future as well as the past.

As Yadin Dudai and Mary Carruthers have discussed (Nature 434, 567; 2005), people draw on past experiences in order to imagine and simulate episodes that might occur in their personal futures. When we imagine different versions of tomorrow's big meeting or what might happen during next week's trip, for example, we project ourselves into the future based on what we remember from the past. Indeed, information about the past is useful only to the extent that it allows us to anticipate what may happen in the future.

But future events are not exact replicas of pastevents, and a memory system that simply stored rote records would not be wellsuited to simulating future events. A system built according to constructive principles may be a better tool for the job: it can draw on the elements and gist of the past, and extract, recombine and reassemble them into imaginary events that never occurred in that exact form. Such a system will occasionally produce memory errors, but it also provides considerable flexibility.

Although this hypothesis has yet to be subjected to direct experimental tests, there is supporting evidence. Some amnesic patients who remember little from their personal past have similar problems envisaging their future. For example, one patient who suffered from total loss of episodic memory as a result of a head injury was also unable to envisage events in his personal future, including 'this afternoon', 'tomorrow' or 'next summer. Yet this patient performed well on tests requiring him to imagine non-personal information, such as the shapes of animals or the relative sizes of objects.

Other studies indicate that severely depressed patients think about both past and future events in an overlygeneral, nonspecific manner. Neuroimaging studies from our laboratory and others reveal striking commonalities in the brain networks that are activated when people remember past episodes and imagine future ones - for example, the hippocampus may recombine details from past events into novel future events.

For more than 100 years, memory has been the object of experimental studies that have focused almost exclusively on its role in preserving and recovering the past. We think it is time to try to understand some of memory's errors by looking to the future. Daniel L. Schacter and Donna Rose Add is are in the Department of Psychology, Harvard University, 33 Kirkland St, Cambridge, Massachusetts 02138, USA.

PURTHERREADING

Schacter, D. L. The Seven Sins of Memory (Houghton Miffiin, 2001).

Suddendort T.\& Corballis, M.C. Genet. Soc. Gen Aschal. Monographs 123, 133-167 (1997).

Tulving E Amu Rev. Asychal. 53, 1-25(2002). 